\title{
Multi-Objective Economic Dispatch of Cogeneration Unit with Heat Storage Based on Fuzzy Chance Constraint
}

\author{
Xiuyun Wang ${ }^{1}$, Junyu Tian ${ }^{1}$, Rutian Wang ${ }^{1, *} \mathbb{0}$, Jiakai $\mathrm{Xu}^{2}{ }^{2}$, Shaoxin Chen ${ }^{1}$, Jian Wang ${ }^{3}$ and \\ Yang Cui ${ }^{1}$ \\ 1 Key Laboratory of Modern Power System Simulation and Control \& Renewable Energy Technology, Ministry \\ of Education, Northeast Electric Power University, Jilin 132012, China; wangxiuyun@neepu.edu.cn (X.W.); \\ 2201600224@neepu.edu.cn (J.T.); 2201600093@neepu.edu.cn (S.C.); cuiyang@neepu.edu.cn (Y.C.) \\ 2 State Grid Weifang power supply company, Weifang, Shandong 252000, China; xujiakai@neepu.edu.cn \\ 3 State Grid Sanmenxia power supply company, Sanmenxia, Henan 472000, China; 2201500033@neepu.edu.cn \\ * Correspondence: wangrutian@neepu.edu.cn; Tel.: +86-0432-6480-6691
}

Received: 20 November 2018; Accepted: 24 December 2018; Published: 29 December 2018

check for updates

\begin{abstract}
With the increasing expansion of wind power, its impact on economic dispatch of power systems cannot be ignored. Adding a heat storage device to a traditional cogeneration unit can break the thermoelectric coupling constraint of the cogeneration unit and meet the economic and stable operation of a power system. In this paper, an economy-environment coordinated scheduling model with the lowest economic cost and the lowest pollutant emissions is constructed. Economic costs include the cost of conventional thermal power generating units, the operating cost of cogeneration units, and the operating cost of wind power. At the same time, green certificate costs are introduced into the economic costs to improve the absorption of wind power. Pollutant emissions include $\mathrm{SO}_{2}$ and $\mathrm{NO}_{\mathrm{x}}$ emissions from conventional thermal power units and cogeneration units. The randomness and uncertainty of wind power output are fully considered, and the prediction error of wind power is fuzzy treated according to the fuzzy random theory, and the electric power balance and spinning reserve fuzzy opportunity conditions are established, which are converted into the explicit equivalent. The improved multi-objective particle swarm optimization (MOPSO) was used to solve the model. With this method, the validity of the model is verified by taking a system with 10 machines as an example.
\end{abstract}

Keywords: cogeneration unit; wind power; green certificate; fuzzy stochastic theory; multi-objective scheduling model; multi-objective particle swarm optimization (MOPSO)

\section{Introduction}

In recent years, the energy crisis, the greenhouse effect and air pollution have become more and more serious. As a kind of abundant renewable resource, wind energy plays an important role in alleviating the crisis of traditional fossil energy and solving environmental damage [1,2]. The operation characteristics of thermoelectric coupling of cogeneration unit further limit the grid-connection consumption of other new energy sources such as wind power [3]. The installation of heat storage device on the cogeneration unit can effectively solve the problem of thermoelectric coupling [4,5].

The randomness and uncertainty of wind power leads to many access and scheduling problems [6-8]. More and more scholars consider the randomness of wind power into the economic dispatch of a power system. Álvaro Lorca and Andy Sun proposed an adaptive robust optimization model for multi-cycle economic scheduling, introduced the concept of dynamic uncertain sets and the method of constructing uncertain time and space correlation models. Simulation results showed 
that this method is superior to the existing robust optimization model in cost and reliability [9]. In references [10-12], the uncertainty of wind power output is dealt with by using stochastic simulation technology. Xiong Hu et al. took the output and load of a large-scale intermittent power supply as fuzzy parameters, and studied the clear equivalence class of fuzzy opportunity constraints with multiple fuzzy parameters, which was used to deal with the opportunity constraints [13]. The above studies fully consider the randomness and uncertainty of wind power, and the established model meets the actual operation requirements of a power system.

Many scholars have carried out a lot of research on the joint scheduling of cogeneration units and wind power. Mueller $S$ et al. studied and discussed the potential of cogeneration and heat pump electricity in Germany's future energy system to balance the fluctuations of renewable energy power generation [14]. Lu et al. established a low-carbon economic dispatch model for an integrated electric and thermal energy system. They proposed a model of minimum coordination between the rate of heat storage and the power of the electric boiler under the limit of wind power consumption, and compared the influence of different positions of the electric boiler on the heat loss of the heating network [15]. In references [16,17], the researchers established the combined system of the wind-electric boiler and heat-storage cogeneration unit, which can effectively reduce the peak valley difference of the wind abandoning quantity and electric load by increasing the load space. Through the above studies, it can be seen that the increase of thermal auxiliary equipment can effectively decouple the electric and thermal characteristics of the cogeneration unit, and through reasonable unit scheduling, the grid-connection consumption of new energy such as wind power can be achieved and operation costs can be reduced. Nguyen T.T. et al. proposed a cuckoo search algorithm (CSA) based on the breeding behavior of the cuckoo, which has the advantages of fewer control parameters, high solution quality and a fast calculation speed [18]. Chanda C K et al. proposed an optimization algorithm based on biogeography for the thermoelectric joint economic dispatch problem. The model is the optimal power and heat distribution within the operating range to meet the electrical load demand and to minimize the total cost [19]. In references [20-22], the researchers developed several optimal scheduling models to achieve economic coordinated operation based on the micro-grid system of the cogeneration units.

Most of the above studies only discussed the joint scheduling problem of cogeneration units and wind power from the perspective of a single objective, and did not consider the environmental pollution caused by long-term higher power levels of cogeneration units. Because economic benefit and environmental benefit are interrelated, a single goal cannot meet the actual operational demand of power systems. Therefore, in this paper, the cost of coal burning and wind power operation are comprehensively considered in the joint dispatching model of heat storage, heat generation and power generation combined with wind power, and the transaction cost of a green certificate is introduced into the economic cost. Meanwhile, the target function of pollutant emission is also taken into account in the scheduling model to further promote the low-carbon emission reduction of the system economic dispatch. In addition, aiming at the randomness and uncertainty of wind power output, this paper adopts the fuzzy random theory to deal with the prediction error of wind power, and establishes the spinning reserve fuzzy opportunity constraint condition to transform it into the cleaning equivalent. The improved MOPSO was used to optimize the scheduling model, and finally the validity and rationality of the model were verified by an example.

The structure of this article is as follows: Section 2 introduces the operating characteristics of cogeneration units. Section 3 introduces the fuzzy opportunity constraint. Section 4 builds a multi-objective scheduling model that considers green certificates. Section 5 converts the fuzzy model into a clear equivalence class. Section 6 verifies the validity of the model in this paper through an example analysis. Finally, Section 7 summarizes the conclusions.

\section{Operating Characteristics of a Cogeneration Unit}

The cogeneration unit is divided into four types according to the different electric and thermal characteristics. This paper conducts relevant research based on the cogeneration units of exhaust 
gas. A conventional cogeneration unit has thermoelectric coupling characteristics, which greatly limits the grid-connection consumption of new energy generation such as wind power. The addition of thermal energy storage devices by a traditional cogeneration unit can break the thermo-electric coupling characteristics of the unit and at the same time achieve the purpose of improving wind power and other new energy generation.

The electric and thermal characteristics of the conventional cogeneration unit are shown in Figure 1. In the figure, $c_{m}$ is the elastic coefficient of electrical power and thermal power under back pressure. $c_{v}$ is the reduction of electric power generated by more than one unit of heating heat when the intake volume remains constant. $P_{h . m e d}$ is the heating power of the steam turbine with the minimum generating power of the unit. $P_{h T, \max }$ is the maximum heating power of the unit. $P_{e, \min }$ and $P_{e, \max }$ are the minimum and maximum active power output of the unit under the purification condition.

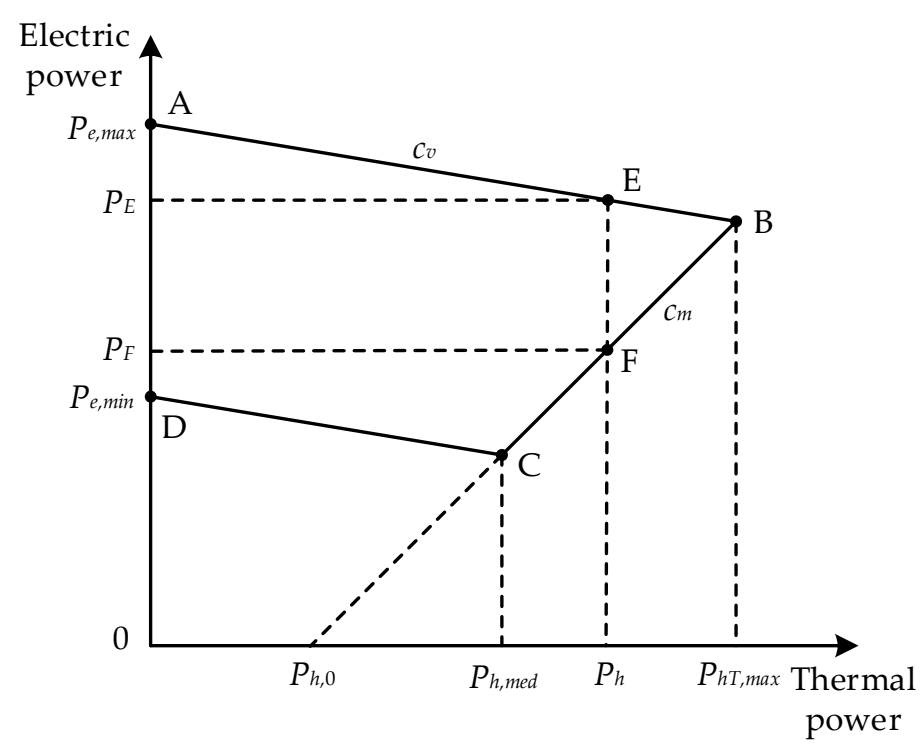

Figure 1. Electric and thermal characteristics of conventional cogeneration unit.

Adding heat storage device to the conventional cogeneration unit can decouple the electric and thermal characteristics of the unit. At this time, the electric and thermal characteristics are shown in Figure 2. For a certain power generation (such as $P_{B}$ ), set the maximum heating power of the turbine to $P_{h T, \max }$, through the heat release of the heat storage device, its overall maximum heating power will increase by $P_{h, f \max }$ to $P_{h T, \max }+P_{h, f \max }$, which is equivalent to AB and BC being shifted by the whole to the right by $B$. In addition, since the minimum heating power $(C D)$ exists when the steam turbine power is between $P_{e, \min }$ and $P_{C}$, the minimum heating power is shifted to the left $P_{h \text { ffmax }}$ after the heat storage device is disposed. After the heat storage device is configured, the overall operating range of the pumping unit changes from ABCD to AGIJKL. It can be seen that for a certain heating level $P_{h}$, after the heat storage device is configured, the power generation power adjustment range of the unit is changed from $\left[P_{F}, P_{E}\right]$ to $\left[P_{M}, P_{H}\right]$, which significantly improves the adjustability of the unit and reduces the thermoelectricity coupling characteristics. 


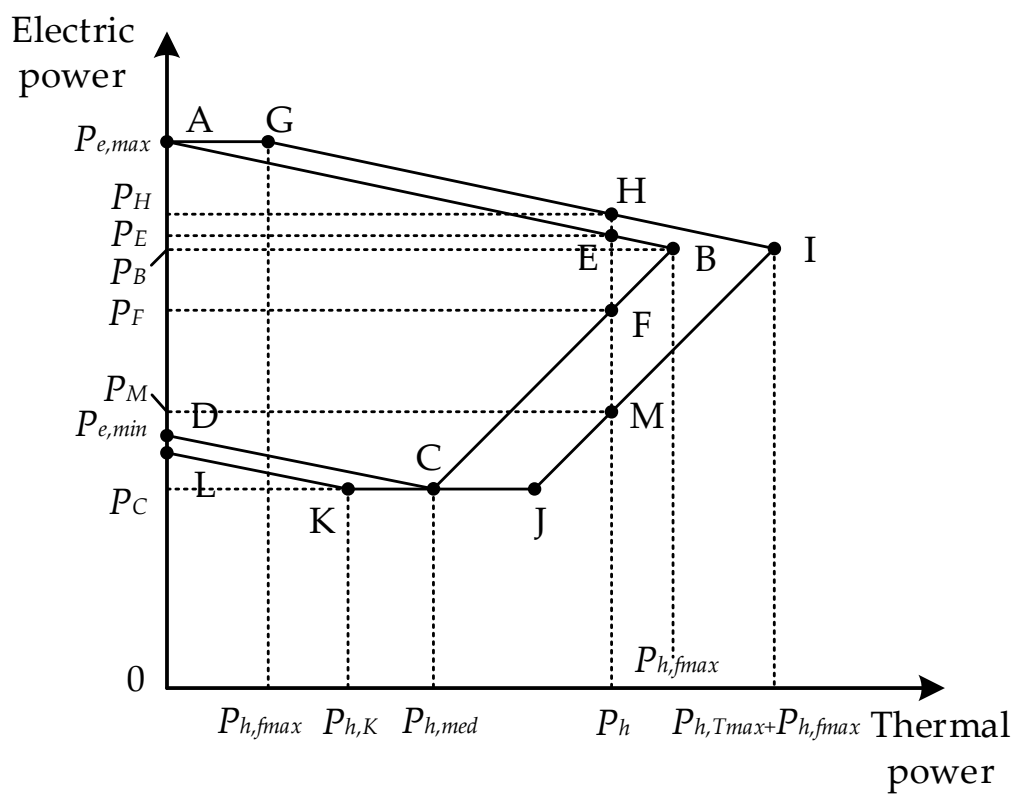

Figure 2. Electric and thermal characteristics of conventional cogeneration unit with heat storage.

\section{Fuzzy Chance Constrained Programming}

\subsection{Fuzzy Opportunity Constraints Based on Credibility Theory}

Fuzzy decision and random decision are two common theories to solve the uncertainty phenomenon, which solves the mathematical problems with fuzzy variables and random variables respectively. The traditional fuzzy theory does not establish a complete axiomatization system, so that confusion often occurs in the application. For example, the membership degree is not self-dual, and the actual membership of 1 and 0 is not an inevitable event. Fuzzy stochastic theory is a fuzzy theory system that combines the theory of opportunity measurement and has a complete axiomatic basis. The optimization problem with constraints containing fuzzy parameters can be expressed as [23]:

$$
\begin{gathered}
\min f(x) \\
\text { s.t. } g(x, \xi) \leq 0
\end{gathered}
$$

where $x$ is the decision vector, $\xi$ is the fuzzy parameter vector, $f(x)$ is the objective function, $g(x, \xi)$ is the constraint function.

Due to the existence of ambiguity, the constraint cannot give a certain feasible set, the opportunity under the credibility measure is used to constrain the output, that is, the constraint condition is established with a certain confidence level $\alpha$, and it is expressed as:

$$
\operatorname{Cr}\{g(x, \xi) \leq 0\} \geq \alpha
$$

where $\alpha$ is the confidence level; $C r\{\cdot\}$ is the probability of the event $\{\cdot\}$.

Event $A$ can be expressed by a credibility measure $C r$, which is equivalent to a probability measure in probability theory, with self-duality. The expression of the credibility measure $\mathrm{Cr}$ is:

$$
C r(\xi \in A)=\frac{1}{2}\left[\sup _{x \in A} \mu(x)+1-\sup _{x \in A^{C}} \mu(x)\right]
$$

where $\mu(x)$ is the credibility measure of the event $A$; $\sup \{\cdot\}$ is the upper limit function; $A^{C}$ is the opposite event $A$. 


\subsection{The Credibility Distribution of Wind Power Prediction Error}

There are three common forms of wind power fuzzy modeling: one is to directly model the wind power output based on historical data [24]; the other is to directly model the uncertainty of wind power through simulation technology [25]; the third is to transform the ambiguity of wind power into the ambiguity of prediction error, considering the predicted value as deterministic, and fuzzy model as the error [26]. This paper takes the third form. The forecast error of wind power is:

$$
\lambda_{w}=\frac{P_{w r}-P_{w}}{P_{w r}} \times 100 \%
$$

where $\lambda_{w}$ is the wind farm power prediction error; $P_{w r}$ and $P_{w}$ are the predicted power and actual power of the wind farm respectively.

The membership degree of the prediction error is expressed by the Cauchy distribution as:

$$
\mu_{w}=\left\{\begin{array}{l}
\frac{1}{1+\sigma\left(\frac{\lambda_{w}}{E_{w+}}\right)^{2}}, \varepsilon_{w}>0 \\
\frac{1}{1+\sigma\left(\frac{\lambda_{w}}{E_{w w}}\right)^{2}}, \varepsilon_{w} \leq 0
\end{array}\right.
$$

where $\sigma$ is the weight; $E_{w+}$ and $E_{w-}$ are the statistical average of positive error and negative error of power respectively.

According to Equation (3), the credibility measure of the prediction error $\xi$ is:

$$
C r\left(\xi \leq \lambda_{w}\right)= \begin{cases}1-\frac{1}{2\left[1+\sigma\left(\frac{\lambda_{w}}{E_{w+}}\right)^{2}\right]}, & \varepsilon_{w}>0 \\ \frac{1}{2\left[1+\sigma\left(\frac{\lambda_{w}}{E_{w+}}\right)^{2}\right]}, & \varepsilon_{w} \leq 0\end{cases}
$$

\section{Multi-Objective Optimization Scheduling Model Considering Green Certificates}

\subsection{Objective Function}

The economic indicators of this paper take into account the cost of a conventional thermal power generating unit, the operating cost of a cogeneration unit, the operating cost of wind power and the cost of green certificates; the environmental indicators take into account the $\mathrm{SO}_{2}$ and $\mathrm{NO}_{\mathrm{x}}$ emissions of a conventional thermal power unit and a cogeneration unit. Based on the above indicators, a green low-carbon multi-objective economic dispatching model with combined heat and power cogeneration unit and wind power is constructed.

The objective function of system economic cost can be expressed as:

$$
\min F=F_{G}+F_{e}+F_{w}+F_{R}
$$

where $F$ is the economic cost of the system within the scheduling period $T ; F_{G}$ is the economic cost of thermal power unit operation during the scheduling period $T ; F_{e}$ is the economic cost of cogeneration unit operation during the scheduling period $T ; F_{w}$ is the economic cost of the wind turbine operation during the scheduling period $T ; F_{R}$ is the green certificate costs of the system during the scheduling period $T$.

The objective function of pollutant emission can be expressed as:

$$
\min E=E_{G}+E_{H}
$$

where $E_{G}$ and $E_{H}$ are the $\mathrm{SO}_{2}$ and $\mathrm{NO}_{\mathrm{x}}$ emissions of conventional thermal power units and cogeneration units during the scheduling period $T$. 


\subsubsection{Green Certificate Cost}

We define the electricity generated by the thermal power unit and cogeneration unit as non-green power, and the electricity generated by wind power unit as green power. The power system can redeem and receive a green certificate for every $1 \mathrm{MW} \cdot \mathrm{h}$ of green energy produced. The power system can redeem and receive a green certificate for every $1 \mathrm{MW} \cdot \mathrm{h}$ of green energy produced. The government allocates a certain amount of green energy production indicators according to the system's output. The system uses green energy to exchange green certificates, and to hand in the required green certificates before the deadline, otherwise it will face high fines.

The government allocates certain green energy production indicators according to the output of the power system. Then the green certificate index given by the government to the system during the unit period is:

$$
R_{q}^{t}=\beta P_{D}^{t} / \delta
$$

where $R_{q}^{t}$ is the green certificate production index of the system required by the government within the unit period $t ; \beta$ is the system's green power distribution quota; $\delta$ is the green electrical energy required for the conversion unit green certificate; $P_{D}^{t}$ is the sum of all conventional thermal power units, wind power units and cogeneration units in the unit period $t$, and the calculation formula is as follows:

$$
P_{D}^{t}=\sum_{i=1}^{n} P_{G i}^{t}+\sum_{j=1}^{m} P_{e j}^{t}+P_{w}^{t}
$$

where $n$ is the number of conventional thermal power units; $P_{G i}^{t}$ is the power output of thermal power unit $i$ in unit period $t ; m$ is the number of cogeneration units; $P_{e j}^{t}$ is the electric output of the cogeneration unit $j$ in the unit period $t ; P_{w}^{t}$ is the electric output of the wind farm in the unit period $t$.

Among the electric power systems with wind farms, only the electric energy produced by the wind farm is green electric energy. Then the amount of green certificate convertible by the system in the unit time $t$ is:

$$
R_{p}^{t}=P_{w}^{t} / \delta
$$

where $R_{p}^{t}$ refers to the green certificate amount of green power conversion produced by the system in period $t$.

The green certificate transaction process of the power system analyzed in this paper has three conditions: (1) the amount of green certificates exchanged by the system is greater than the amount of government indicators, and the surplus green certificates are sold for profit; (2) the amount of green certificates exchanged by the system is smaller than the government indicator, but larger than the difference between the government indicator and the amount of green certificates available for purchase, and the green certificate purchase cost shall be paid; (3) the amount of green certificates exchanged by the system is smaller than the amount of government indicators and the amount of green certificates available for purchase. In addition to the purchase cost of green certificates, a fine of the amount of deficiency shall be paid. The calculation formula is as follows:

$$
\begin{gathered}
F_{R}^{t}=\left\{\begin{array}{lc}
K_{R}\left(R_{q}^{t}-R_{p}^{t}\right), & R_{q}^{t} \geq R_{p}^{t} \\
K_{R}\left(R_{p}^{t}-R_{q}^{t}\right), & R_{q}^{t}-R_{L}^{t} \leq R_{p}^{t} \leq R_{q}^{t} \\
K_{R} R_{L}^{t}+K_{H}\left(R_{q}^{t}-R_{L}^{t}-R_{p}^{t}\right), & R_{p}^{t} \leq R_{q}^{t}-R_{L}^{t}
\end{array}\right. \\
R_{L}^{t}=\varphi R_{q}^{t} \\
F_{R}=\sum_{t=1}^{T} F_{R}^{t}
\end{gathered}
$$


where $K_{R}$ is the transaction price of green certificate; $K_{H}$ is the price of green certificate fines; $R_{L}^{t}$ is the amount of the green certificate that can be purchased by the system within the unit period of $t ; \varphi$ is the purchase margin of green certificate; $F_{R}^{t}$ is the green certificate cost of the system within unit period $t$.

\subsubsection{Conventional Thermal Power Unit Power Generation Cost}

As a controllable power source, the conventional thermal power unit mainly includes the fuel cost and start-stop cost of the unit. The calculation formula is as follows:

$$
F_{G}=f_{1}\left(P_{G i}^{t}\right)+f_{2}\left(u_{i}^{t}\right)
$$

where $f_{1}$ represents the fuel cost of a conventional thermal power unit; $f_{2}$ represents the start-stop cost of the conventional thermal power unit; $u_{i}^{t}$ indicates the running state of the conventional thermal power unit $i$ at period $t, u_{i}^{t}=1$ means running, $u_{i}^{t}=0$ means stop.

The fuel cost and start-stop cost of a conventional thermal power unit are calculated as follows:

$$
\begin{gathered}
f_{1}\left(P_{G i}^{t}\right)=\sum_{t=1}^{T} \sum_{i=1}^{n} u_{i}^{t}\left[a_{i}\left(P_{G i}^{t}\right)^{2}+b_{i} P_{G i}^{t}+c_{i}\right] \\
f_{2}\left(u_{i}^{t}\right)=\sum_{t=1}^{T} \sum_{i=1}^{n}\left[u_{i}^{t}\left(1-u_{i}^{t-1}\right) s_{i}\right] \\
s_{i}=\psi_{i}+\eta_{i}\left(1-e^{-T_{G i t}^{o f f}} / \tau_{i}\right.
\end{gathered}
$$

where $a_{i}, b_{i}$, and $c_{i}$ represent the fuel cost coefficients of the conventional thermal power unit $i$. $s_{i}$ represents the starting cost of the conventional thermal power unit $i . \psi_{i}, \eta_{i}$ and $\tau_{i}$ are the starting cost coefficients of the conventional thermal power unit.

\subsubsection{Operating Cost of Cogeneration Unit}

For a cogeneration unit, the operating cost should be based on thermal output and electrical output. The electric and thermal output are converted into electric power under pure condensation conditions, and the calculation formula is as follows:

$$
F_{e}=\sum_{t=1}^{T} \sum_{j=1}^{m}\left[a_{j r}\left(P_{e j}^{t}+c_{v} P_{h j}^{t}\right)^{2}+b_{j r}\left(P_{e j}^{t}+c_{v} P_{h j}^{t}\right)+c_{j r}\right]
$$

where $P_{h j}^{t}$ is the heat power of the cogeneration unit at time $t ; a_{j r}, b_{j r}$ and $c_{j r}$ are the fuel cost coefficients of the cogeneration unit.

\subsubsection{Wind Power Operating Costs}

Wind power relies on wind energy and does not generate coal consumption costs during operation. In this paper, the operating cost of wind power is approximated as the linear relationship of wind power. The calculation formula is as follows:

$$
F_{w}=\sum_{t=1}^{T} k_{w} P_{w}^{t}
$$

where $k_{w}$ is the operating and maintenance cost coefficient of the wind farm.

\subsubsection{Pollutant Emission}

Conventional thermal power units and cogeneration units generate $\mathrm{SO}_{2}, \mathrm{NO}_{\mathrm{x}}$ and other polluting gases during operation which will have a certain impact on the ecological balance (such as smog, acid 
rain, ozone layer damage and the greenhouse effect). The calculation formulas for $E_{G}$ and $E_{H}$ of pollutant emissions from conventional thermal power unit and combined heat and power unit are as follows:

$$
\begin{aligned}
& E_{G}=\frac{f_{1}}{R_{m}}\left(J_{S}+J_{N}\right) \\
& E_{H}=\frac{F_{e}}{R_{m}}\left(J_{S}+J_{N}\right)
\end{aligned}
$$

where $R_{m}$ is the unit price of coal burning; $J_{S}$ and $J_{N}$ are the emissions of $\mathrm{SO}_{2}$ and $\mathrm{NO}_{\mathrm{x}}$ when one ton of coal is used for power generation.

\subsection{Constraints}

(1) Power balance constraints

Electric power balance constraints:

On the basis of ignoring the network transmission loss, the sum of the output electric power of each generator set is equal to the grid load. The expression is as follows:

$$
\operatorname{Cr}\left\{\sum_{i=1}^{n} P_{G i}^{t}+\sum_{i=1}^{m} P_{e j}^{t} \geq P_{l}^{t}+P_{w r}^{t} \xi\right\} \geq \alpha
$$

where $P_{l}^{t}$ is the electrical load in period $t ; P_{w r}^{t}$ is the predicted wind power value at period $t$.

Thermal power balance constraint:

Ignoring the heat loss during the transmission process, the sum of the direct heating power of the cogeneration unit and the heating power of the heat storage device is equal to the heat load value. The expression is as follows:

$$
P_{h j}^{t}+S_{h}^{t}=P_{h l}^{t}
$$

where $S_{h}^{t}$ is the heating power of the heat storage device; $P_{h l}^{t}$ is the heat load.

(2) Constraints of conventional thermal power units.

Unit output constraint:

$$
P_{G i, \min } \leq P_{G i}^{t} \leq P_{G i, \max }
$$

where $P_{G i, \max }$ and $P_{G i, \min }$ respectively represent the maximum and minimum output of conventional thermal power unit $i$.

Gradient constraint:

$$
\left\{\begin{array}{l}
P_{G i}^{t}-P_{G i}^{t-1} \leq P_{u, i} \\
P_{G i}^{t-1}-P_{G i}^{t} \leq P_{d, i}
\end{array}\right.
$$

where $P_{u, i}$ and $P_{d, i}$ respectively represent the maximum upward and downward slope climbing rate of conventional thermal power unit $i$.

Units start and stop time constraint:

$$
\left\{\begin{array}{l}
T_{\text {Git }}^{o n} \geq T_{\text {Git,min }}^{o n} \\
T_{\text {Git }}^{o f f} \geq T_{\text {Git,min }}^{o f f}
\end{array}\right.
$$

where $T_{G i t}^{o n}$ and $T_{G i t}^{o f f}$ are the continuous starting and stopping time of the thermal power unit $i$ within the unit period $t ; T_{G i t, m i n}^{o n}$ and $T_{G i t, m i n}^{o f f}$ are the minimum startup and shutdown times of the thermal power unit $i$.

(3) Constraints of the cogeneration unit.

Electrical output constraint:

$$
P_{e j, \min } \leq P_{e j}^{t} \leq P_{e j, \max }
$$

where $P_{e j, \max }$ and $P_{e j, \min }$ are the upper and lower limits of electrical output of the cogeneration unit $j$. 
Thermal output constraint:

$$
0 \leq P_{h j}^{t} \leq P_{h j, \max }
$$

where $P_{h j, \text { max }}$ is the upper limit of thermal output of the cogeneration unit.

Gradient constraint:

For the cogeneration unit, the slope climbing ratio constraint requires us to convert the electric power and thermal power into the electric power under the purified condition (the conversion method is as shown in Equation (19)). The specific constraint is as follows:

$$
\left\{\begin{array}{l}
P_{e j}^{t}-P_{e j}^{t-1} \leq P_{u j}^{r} \\
P_{e j}^{t-1}-P_{e j}^{t} \leq P_{d j}^{r}
\end{array}\right.
$$

where $P_{u j}^{r}$ and $P_{d j}^{r}$ are the maximum upward and downward climb rates of cogeneration units.

(4) Reserve constraint.

$$
\operatorname{Cr}\left[\sum_{i=1}^{n} u_{i}^{t} P_{G i, \max }+\sum_{j=1}^{m} P_{e j, \max } \geq P_{l}^{t}+R_{u}^{t}+P_{w r}^{t} \xi\right] \geq \alpha
$$

where $R_{u}^{t}$ is the spare for the load of period $t$.

(5) Heat storage device constraint.

Heat storage capacity constraint:

$$
H_{c, \min } \leq H_{c}^{t} \leq H_{c, \max }
$$

where $H_{c}^{t}$ is the heat storage capacity of the heat storage device at period $t ; H_{c, \max }$ and $H_{c, \min }$ are the upper and lower limits of heat capacity of the heat storage device.

Power constraint of heat storage and release of heat storage device:

$$
\left\{\begin{array}{l}
H_{c}^{t}-H_{c}^{t-1} \leq P_{h j, c \max } \\
H_{c}^{t-1}-H_{c}^{t} \leq P_{h j, f \max }
\end{array}\right.
$$

where $P_{h j, c m a x}$ and $P_{h j, f m a x}$ are the maximum heat storage and exothermic power of the heat storage device.

Constraint of heat storage and release at the same time:

$$
S_{h j, c}^{t} \cdot S_{h j, f}^{t}=0
$$

where $S_{h j, c}^{t}$ and $S_{h j, f}^{t}$ are the heat storage and exothermic power of the heat storage device at period $t$, and the product of zero indicates that heat storage and heat release cannot take place simultaneously.

Heat storage constraint at the beginning and end of heat storage device:

$$
H_{c}^{0}=H_{c}^{T}
$$

where $H_{c}^{0}$ and $H_{c}^{T}$ are the starting and ending values of heat storage in one scheduling period of the heat storage device.

\section{Fuzzy Chance Constrained Decision Model}

In this paper, we use fuzzy equivalence classes to process fuzzy models. According to the opportunity function $g(x, \xi)$ in Equation (3), when $g(x, \xi)=\xi-h(x), C r=[g(x, \xi) \leq 0] \geq \alpha$ is established, at this time $h(x)$ $\geq K_{\alpha}$. Among them:

$$
K_{\alpha}= \begin{cases}\inf \left\{K \mid K=\mu^{-1}(2 \alpha)\right\}, & \alpha<\frac{1}{2} \\ \sup \left\{K \mid K=\mu^{-1}(2(1-\alpha))\right\}, & \alpha \geq \frac{1}{2}\end{cases}
$$


For the problems described in Equations (24) and (32), the confidence level generally needs to be greater than 0.5. Therefore, the Equation (7) and the Equations (24) and (32) are equivalent to:

$$
\begin{cases}\frac{\sum_{i=1}^{n} u_{i}^{t} P_{G i, \max }+\sum_{j=1}^{m} P_{e j, \max }-\left(P_{l}^{t}+R_{u}^{t}\right)}{P_{w}^{t}} \geq K_{a w}=\sup \left\{K \mid K=\mu_{w}^{-1}(2(1-\alpha))\right\}, & \alpha<\frac{1}{2} \\ \frac{\sum_{i=1}^{n} P_{G i}^{t}+\sum_{j=1}^{m} P_{e j}^{t}-P_{l}^{t}}{P_{w}^{t}} \geq K_{a w}=\sup \left\{K \mid K=\mu_{w}^{-1}(2(1-\alpha))\right\}, & \alpha \geq \frac{1}{2}\end{cases}
$$

Combined with Equation (6), the following conclusions can be obtained:

$$
\left\{\begin{array}{l}
\sum_{i=1}^{n} u_{i}^{t} P_{G i, \max }+\sum_{j=1}^{m} P_{e j, \max } \geq P_{l}^{t}+R_{u}^{t}+P_{w}^{t} K_{a w} \\
\sum_{i=1}^{n} P_{G i}^{t}+\sum_{j=1}^{m} P_{e j}^{t} \geq P_{l}^{t}+P_{w}^{t} K_{a w} \\
K_{a w}=E_{w+}\left[\frac{2 \alpha-1}{2 \sigma(1-\alpha)}\right]^{\frac{1}{2}}
\end{array}\right.
$$

\section{Case Analysis}

\subsection{Model Solving}

Considering that the multi-objective coordinated scheduling model established in this paper is a multi-stage, nonlinear complex problem, the traditional optimization algorithm is difficult to solve. Therefore, on the basis of the original MOPSO, the weight of inertia and the learning factor are modified to improve the search speed and reduce the local to the most effective level. The update of the particle's velocity and position is as follows:

$$
\begin{gathered}
v_{i, j}^{t+1}=w v_{i, j}^{t}+c_{1} r_{1}\left(p_{i, j}-x_{i, j}^{t}\right)+c_{2} r_{2}\left(p_{g, j}-x_{i, j}^{t}\right) \\
x_{i, j}^{t+1}=x_{i, j}^{t}+v_{i, j}^{t+1}
\end{gathered}
$$

where $t$ is the iteration number of the algorithm, $i$ and $j$ are particle number and dimension. $\mathrm{w}$ is inertia weight, $c_{1}$ and $c_{2}$ are self-learning factors and social learning factors respectively. $r_{1}$ and $r_{2}$ are uniformly distributed random numbers within $(0,1) \cdot p_{i, j}$ is the historical optimal solution of the current particle, and $p_{g, j}$ is the global optimal solution for all particles.

The arctangent function $y=\arctan (x)$ is an increasing function, the function value increases with the increment of the independent variable, but the speed of the function value gradually decreases. When the independent variable value is 1.56 , the function value increases to 1 . The improved inverse tangent function can meet the requirement of the particle swarm optimization (PSO) for the change of inertial weight. The weight improvement strategy is Particle swarm optimization

$$
w(t)=\left(w_{\text {start }}-w_{\text {end }}\right) \times \arctan \left(1.56 \times\left(1-\left(\frac{t}{t_{\text {max }}}\right)^{k}\right)\right)+w_{\text {end }}
$$

where $t$ is the number of iterations; $t_{\max }$ is the maximum number of iterations; $w_{\text {start }}$ is the initial inertia weight; $w_{\text {end }}$ is the termination inertia weight.

The learning factor $c_{1}$ and social factor $c_{2}$ were accelerated by nonlinear inverse cosine, $c_{1}$ increased first and then decreased, while $c_{2}$ decreased first and then increased. The basic idea is that in the initial stage of searching, the particle mainly refers to its historical information $c_{1}$, and in the later stage, it pays more attention to social information $c_{2}$. Constructed as follows:

$$
c_{1}=c_{1 e}+\left(c_{1 s}-c_{1 e}\right)\left[1-\frac{\arccos \left(-2 t / t_{\max }+1\right)}{\pi}\right]
$$




$$
c_{2}=c_{2 e}+\left(c_{2 s}-c_{2 e}\right)\left[1-\frac{\arccos \left(-2 t / t_{\max }+1\right)}{\pi}\right]
$$

where $c_{1 s}$ and $c_{2 s}$ are the initial values of iteration; $c_{1 e}$ and $c_{2 e}$ are the final iteration values; $t$ is the current number of iterations, and $t_{\max }$ is the maximum number of iterations. In this paper, $c_{1 s}=2.5$, $c_{2 s}=0.5 ; c_{1 e}=0.5, c_{2 e}=0.5$.

The initial value of the improved MOPSO is a random particle swarm, and the initial global optimal position is obtained by evaluating each particle. In the iteration process, the particle keeps updating its speed and position by tracking the individual extremum and global extremum. The fitness function is used to evaluate the particle quality, update the new and historical optimal position, and iterate over and over to get the optimal solution. The flowchart is shown in Figure 3.

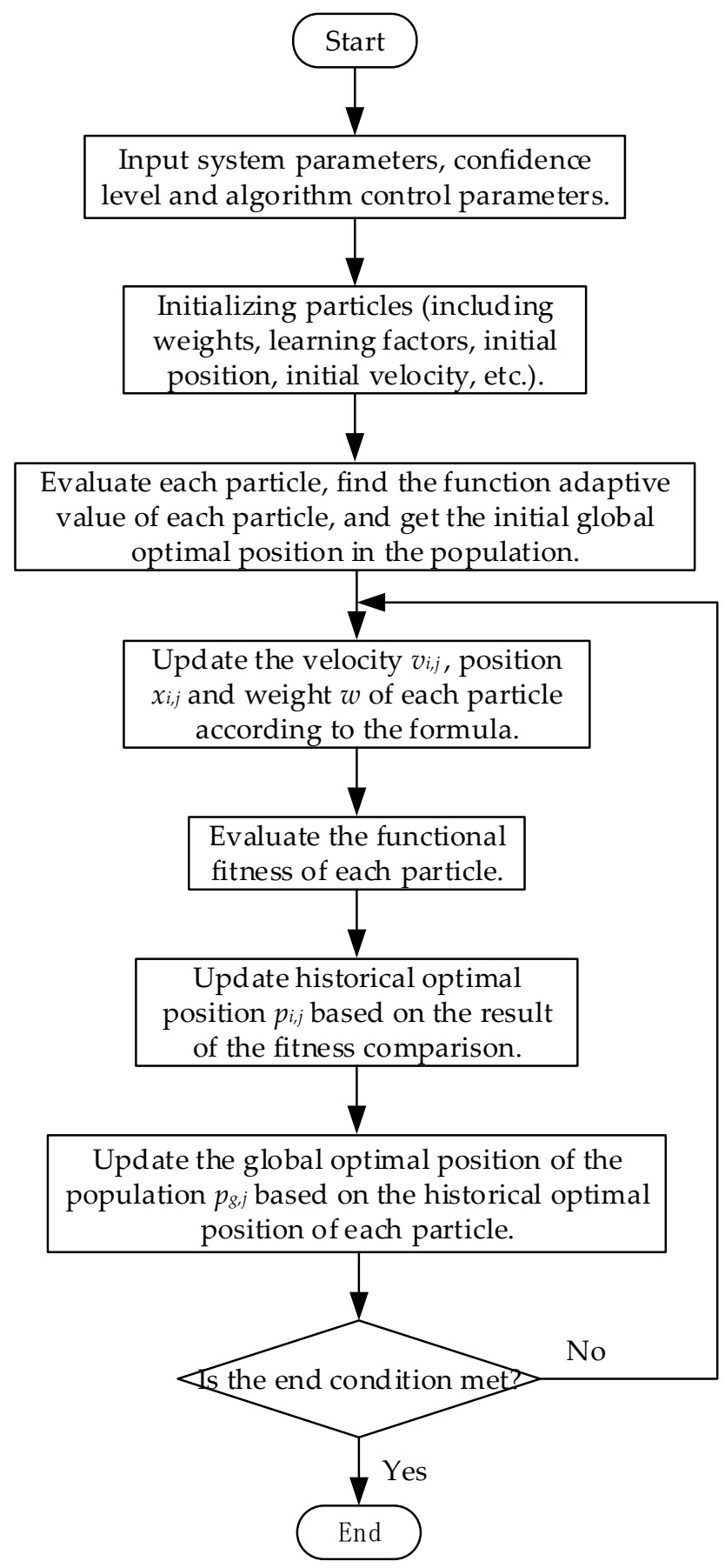

Figure 3. Model solving flow chart. 


\subsection{Basic Data and Result Analysis}

The system analyzed in this paper contains 10 generator sets, 8 of which are conventional thermal power units and 2 are cogeneration units of the same type. The data of conventional thermal power units and cogeneration units are shown in Tables 1 and 2. The predicted values of power load, thermal load and wind power in the dispatching cycle are shown in Figure 4. The reliability parameters of wind power prediction error are distributed as follows: $E_{w+}=E_{w-}=20 \%, \sigma=2.333$, and the confidence level $\alpha$ is 0.85 . The load reserve is set at $5 \%$ of the total load. The system's green power distribution quota $\beta$ is 0.2 , and the green certificate purchase margin $\varphi$ is 0.4 . The green electric energy required to redeem the unit green certificate $\delta$ is $1 \mathrm{MWh} /$ copy. Wind power generation cost coefficient $k_{w}$ is $39 \$ / \mathrm{MW}$, and coal cost $R_{m}$ is $80 \$ / \mathrm{t}$. The transaction price is $3 \$ /$ copy. The price of green certificate fine is $8 \$$ /copy. $J_{S}$ and $J_{N}$ of the units are $8.6 \mathrm{~kg} / \mathrm{t}$ and $7.4 \mathrm{~kg} / \mathrm{t}$.

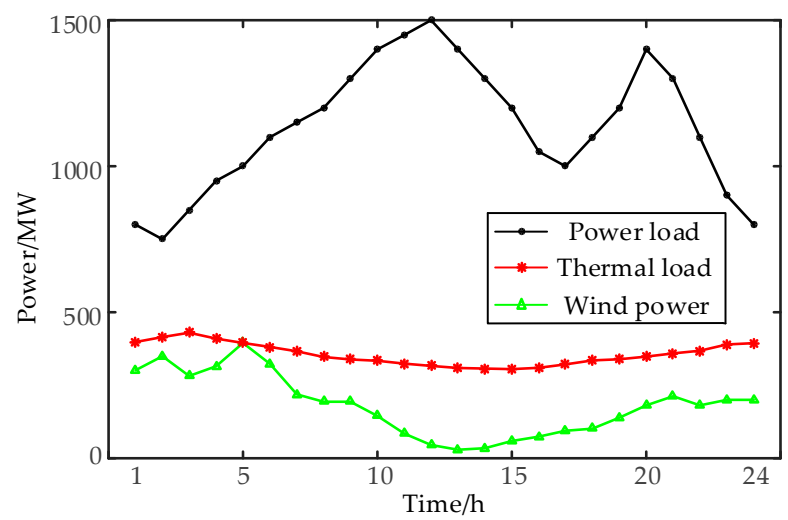

Figure 4. The predicted values of electricity load, thermal load and wind power.

Table 1. The parameters of conventional thermal power units.

\begin{tabular}{|c|c|c|c|c|c|c|c|c|c|c|}
\hline Unit & $\begin{array}{c}R_{u, i} \\
(\mathrm{MW} / \mathrm{h})\end{array}$ & $\begin{array}{c}R_{d, i} \\
(\mathrm{MW} / \mathrm{h})\end{array}$ & $\begin{array}{c}a_{i} \\
\left(\$ \cdot\left(\mathrm{MW}^{-2} \cdot \mathrm{h}^{-1}\right)\right)\end{array}$ & $\begin{array}{c}b_{i} \\
(\$ /(M W \cdot h))\end{array}$ & $\begin{array}{c}c_{i} \\
(\$ / \mathrm{h})\end{array}$ & $\begin{array}{l}P_{G i, \max } \\
\text { MW }\end{array}$ & $\begin{array}{c}P_{G i, \min } \\
\text { MW }\end{array}$ & $\begin{array}{c}\psi_{i} \\
(\$ / h)\end{array}$ & $\begin{array}{c}\eta_{i} \\
(\$ / \mathbf{h})\end{array}$ & $\begin{array}{r}\tau_{i} \\
\text { (h) }\end{array}$ \\
\hline 1 & 130 & 130 & 0.00048 & 16.19 & 1000 & 455 & 150 & 5500 & 5500 & 5 \\
\hline 2 & 90 & 90 & 0.00211 & 16.50 & 680 & 130 & 20 & 550 & 550 & 2 \\
\hline 3 & 40 & 40 & 0.00398 & 19.70 & 450 & 162 & 25 & 700 & 700 & 2 \\
\hline 4 & 40 & 40 & 0.00712 & 22.26 & 370 & 80 & 20 & 170 & 170 & 2 \\
\hline 5 & 40 & 40 & 0.00079 & 27.74 & 480 & 85 & 25 & 200 & 200 & 2 \\
\hline 6 & 40 & 40 & 0.00413 & 25.92 & 660 & 55 & 10 & 30 & 30 & 1 \\
\hline 7 & 40 & 40 & 0.00222 & 27.27 & 665 & 55 & 10 & 30 & 30 & 1 \\
\hline 8 & 40 & 40 & 0.00173 & 27.79 & 670 & 55 & 10 & 30 & 30 & 1 \\
\hline
\end{tabular}

Table 2. The parameters of cogeneration units.

\begin{tabular}{|c|c|c|c|c|c|c|c|c|c|}
\hline Unit & $\begin{array}{c}P_{e j, \max } \\
\mathbf{M W}\end{array}$ & $\begin{array}{c}\boldsymbol{P}_{\boldsymbol{e j}, \min } \\
\mathbf{M W}\end{array}$ & $\begin{array}{l}P_{h j, \max } \\
\mathbf{M W}\end{array}$ & $\begin{array}{c}a_{r} \\
\left(\$ \cdot\left(\mathrm{MW}^{-2} \cdot \mathrm{h}^{-1}\right)\right)\end{array}$ & $\begin{array}{c}b_{r} \\
(\$ /(M W \cdot h))\end{array}$ & $\begin{array}{c}c_{r} \\
(\$ / h)\end{array}$ & $c_{v}$ & $\begin{array}{c}P_{u j}^{r} \\
(\mathrm{MW} / \mathrm{h})\end{array}$ & $\begin{array}{c}P_{d j}^{r} \\
(\mathbf{M W} / \mathbf{h})\end{array}$ \\
\hline 1,2 & 350 & 150 & 400 & 0.00576 & 16.336 & 969.44 & 0.15 & 90 & 90 \\
\hline
\end{tabular}

In this example, three scheduling schemes are compared and analyzed:

- Scheme 1: Take the lowest cost of the system economy as the objective function;

- Scheme 2: Take the minimum pollutant emission of the system as the objective function;

- Scheme 3: Multi-objective scheduling in this paper.

\subsubsection{Analysis of Scheduling Results}

In the three scheduling schemes, the economic cost and pollutant emission results of the system are shown in Table 3. The consumption power of wind power is shown in Figure 3. Green certificate costs of Scheme 3 in each period are shown in Figure 4. 
Table 3. Results of three scheduling schemes.

\begin{tabular}{ccc}
\hline Scheme & The Economic cost, $\boldsymbol{F}(\mathbf{k} \mathbf{\$})$ & Pollutant Emission, $\boldsymbol{E}(\mathbf{t})$ \\
\hline 1 & 567.83 & 96.34 \\
2 & 594.2 & 71.05 \\
3 & 581.75 & 82.32 \\
\hline
\end{tabular}

It can be seen from Table 3 that in the scheduling Scheme 1 with only the lowest system economic cost as the scheduling target, the conventional thermal power unit and the cogeneration unit are given priority to generate electricity with the wind turbine, so that the total economic cost of the system is the lowest. However, because the thermal power units and the cogeneration units emit pollutants while generating electricity, the pollutant emission of the system under this scheme is the highest among the three scheduling schemes. In scheduling Scheme 2 with only the minimum pollutant emissions of the system taken as the scheduling target, the wind turbine is given priority to generate electricity, so the pollutant emissions of the system is minimal. However, since the power generation cost of the wind turbine is higher than that of the thermal power unit and the cogeneration unit, the economic cost of the system is the highest among the three scheduling schemes. In Scheme 3, the scheduling result is between Scheme 1 and Scheme 2 . This scheme not only guarantees the economic efficiency of the system dispatch, but also reduces the pollutant emissions of the system to a certain extent.

In a comprehensive comparison of the above three schemes, Scheme 1 only pursues economic benefits and ignores the negative impact of the system on the environment. On the contrary, Scheme 2 only pursued the lowest emission of pollutants, which resulted in a high economic cost. Scheme 3 not only meets the low economic cost, but also reduces the emission of pollutants, achieving an effective balance between the economic and environmental benefits of the system.

As can be seen from Figure 5, due to the inverse modulating peak characteristic of wind power, wind power is relatively low during the period of $10-18 \mathrm{~h}$ with high electrical load, and all wind power is grid-connected at this time. In the periods of 1-9h and 19-24h with low loads, wind power is relatively high. In order to meet the balance of electric load and thermal load, only a part of wind power can be allowed to be connected to the grid. Wind power consumption of the three scheduling schemes are $55.06 \%, 79.41 \%$ and $66.42 \%$ respectively.

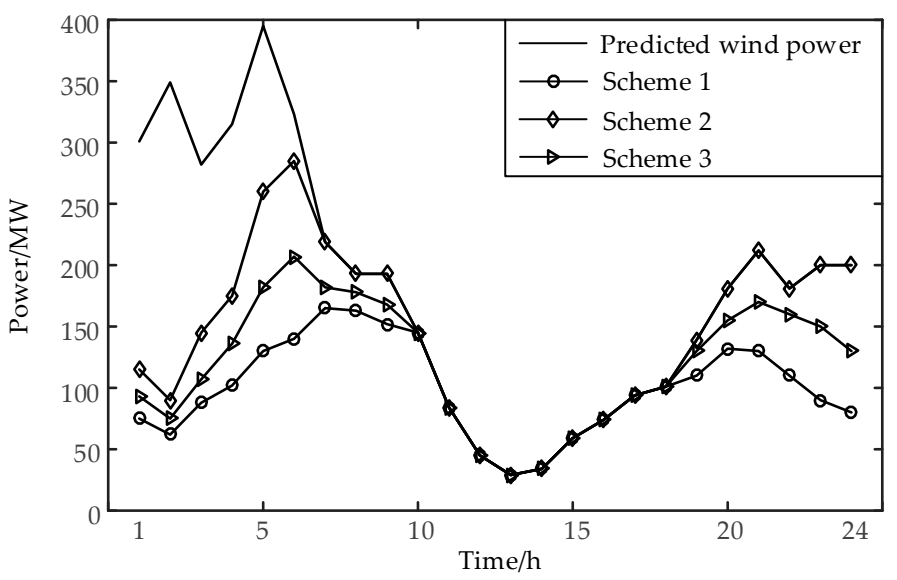

Figure 5. Wind power consumption of three schemes.

As can be seen from Figure 6, during the period of 10-20 h with high load, the wind power is relatively low. The system's green certificate costs during this time include not only the cost of buying the green certificate, but also a large number of fines. In times $1-9 \mathrm{~h}$ and $21-24 \mathrm{~h}$, the system only purchased a small number of green certificates, so the cost is low. It can be seen that green certificate costs are mainly affected by wind power and load. The green certificate fines mainly exist in periods of high load and low wind power. 


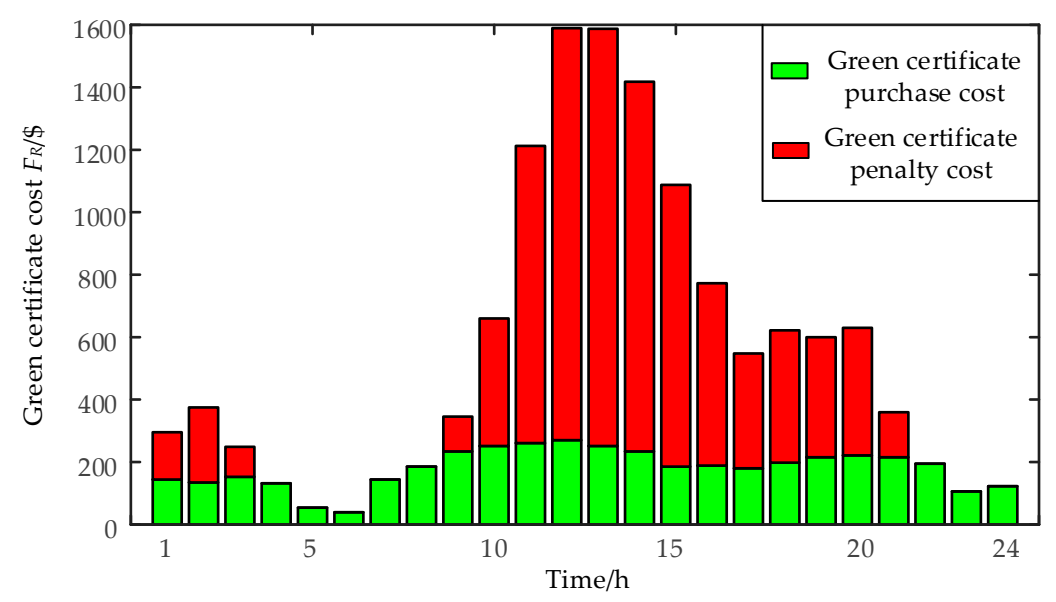

Figure 6. Green certificate in each period.

\subsubsection{Analysis of Different Scheduling Models}

In order to verify the influence of green certificates on the economic dispatch of this paper, two different economic dispatch models were compared in Scheme 3:

- Model 1: Multi-objective scheduling model considering green certificates;

- Model 2: A traditional multi-objective scheduling model that does not consider green certificates.

The scheduling results of the two models are shown in Table 4.

Table 4. Scheduling results for different models.

\begin{tabular}{cccc}
\hline Model & The Economic Cost, $\boldsymbol{F}(\mathbf{k} \mathbf{\$})$ & Pollutant Emission, $\boldsymbol{E}(\mathbf{t})$ & Wind Power Consumption \\
\hline 1 & 581.75 & 82.32 & $66.42 \%$ \\
2 & 572.59 & 89.45 & $58.53 \%$ \\
\hline
\end{tabular}

As shown in Table 4, the economic cost of Model 1 increased by $9.16 \mathrm{k} \$$ compared with Model 2, but at this time, the pollutant emission decreased by $7.13 \mathrm{t}$ and the wind power consumption increased by $7.89 \%$. Therefore, it can be seen that after the introduction of the green certificate in the dispatching model, although the economic cost of the system is increased to some extent, the consumption of wind power is increased, and the pollutant emission is also reduced, which meets the requirements of promoting the development of new energy power generation and energy conservation and emission reductions in China.

\subsubsection{Analysis of Different Parameters}

Under the multi-objective scheduling scheme in this paper (Scheme 3), Figure 5 shows the curve of the change of system economic costs $F$ and pollutant emissions $E$ with the different price of green certificate fine $K_{H}$. Figure 6 shows the curve of green certificate cost $F$ changing with purchase margin $\varphi$. Figure 7 shows the curve of the change of economic $\operatorname{cost} F$ system with the confidence level $\alpha$. 


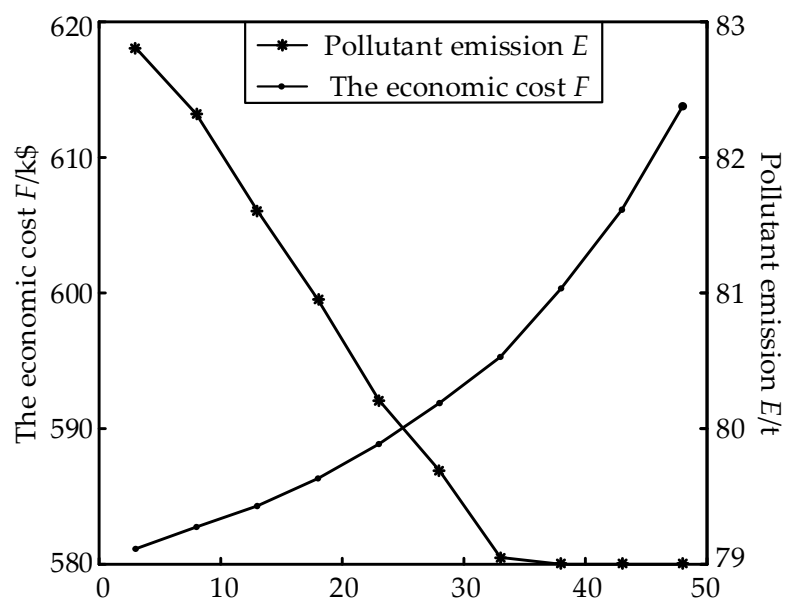

Figure 7. The economic cost and pollutant emission with different price of green certificate fines.

As can be seen from Figure 7, with the increase in the price of green certificate fines $\mathrm{K}_{\mathrm{H}}$, the economic costs $\mathrm{F}$ of the system also increases. However, the pollutant emission of the system tends to decrease with the increase of the price of green certificate fines, and finally tends to be stable. This is because the increase in the price of the green certificate penalty will increase the economic cost of the system, and make the system absorb more wind power to reduce the cost of the green certificate. Due to the relatively high price of green certificate fines, the system economic cost still increases. When the price of green certificate penalty is higher than a certain value, the system cannot continue to increase wind power consumption, the economic cost of the system continues to increase, and the pollutant emission remains at a fixed value. It can be seen that the economic cost and pollutant emission of the system can be controlled reasonably by controlling the price of green certificate fines.

As can be seen from Figure 8, when the green certificate purchase margin $\varphi$ is small, the number of green certificates that can be purchased is small, and the system has to pay a large amount of fines in addition to the purchase cost of the green certificate. As the purchase margin increases, the purchase cost of green certificates increases and the penalty cost decreases. However, since the price of fines is much higher than the purchase price of green certificates, the transaction cost of green certificates is decreasing.

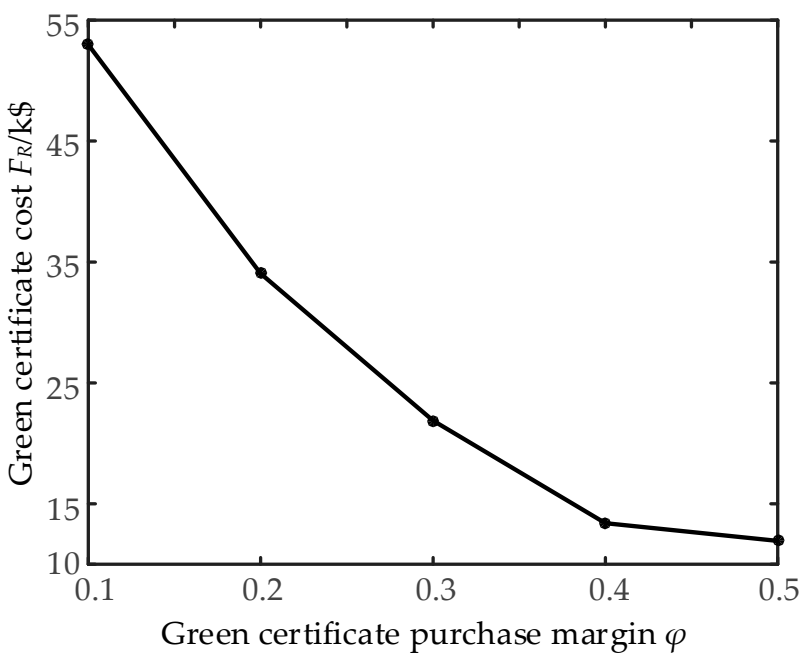

Figure 8. Green certificate cost with different purchase margin.

It can be seen from Figure 9 that when the confidence level $\alpha$ is low, the economic cost of the system $\mathrm{F}$ is small. With the gradual increase of the confidence level $\alpha$, the requirements for the rotation reserve caused by the wind power prediction error are also increasing, the total economic cost $\mathrm{F}$ of the system is gradually increasing, and the risk of the system is gradually decreasing. In actual 
operation, the decision maker controls the risk by controlling the confidence level $\alpha$, and selects a unit combination scheme with the lowest economic cost and meeting the set confidence level.

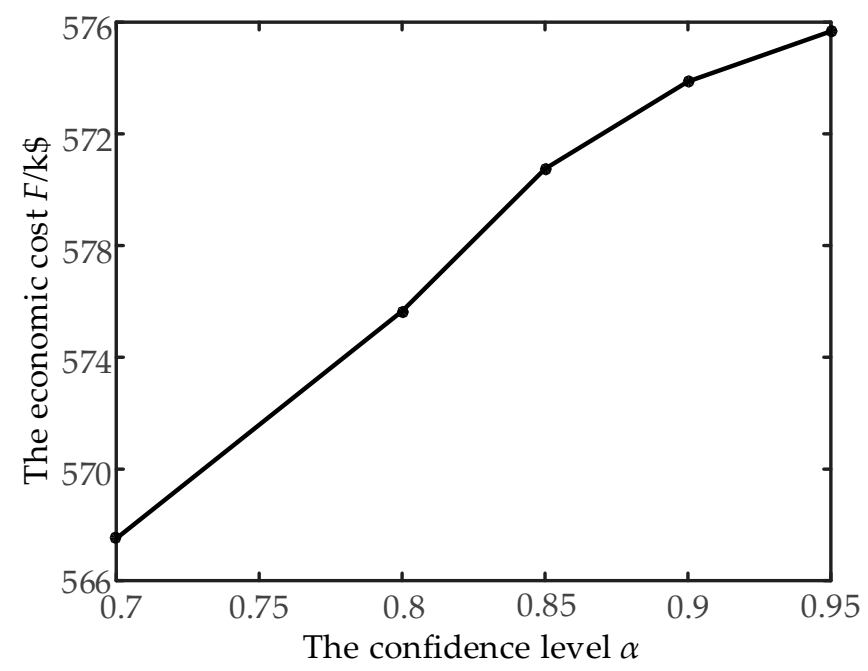

Figure 9. The economic costs with different confidence levels.

\subsubsection{Algorithm Performance Analysis}

In this paper, an improved MOPSO and the traditional MOPSO are used to solve the scheduling model. The comparison results of the economic cost convergence curves of the above two algorithms are shown in Figure 10a, and the comparison results of pollutant emission convergence curves are shown in Figure 10b.

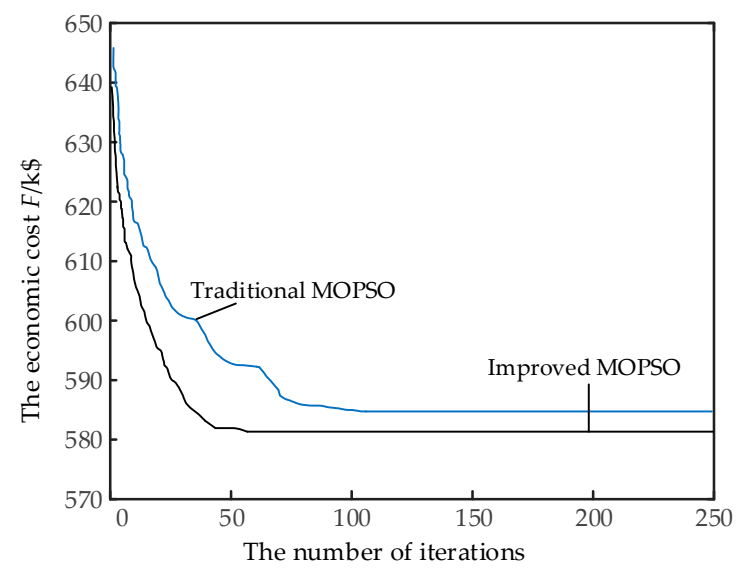

(a)

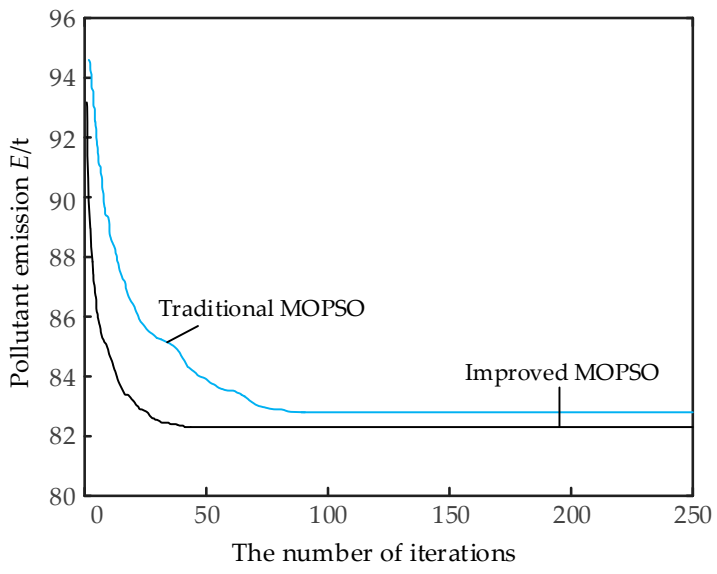

(b)

Figure 10. (a) Comparison of convergency among different algorithms. (b) Comparison of convergency among different algorithms.

It can be seen from two figures that the improved MOPSO proposed in this paper has a faster convergence speed and a stronger global search ability. The improved algorithm is beneficial to the solution of the model.

\section{Conclusions}

In this paper, a multi-objective scheduling model for cogeneration units with heat storage is presented. The model takes into account economic costs and pollutant emissions. In order to further promote wind power consumption, green certificate costs are added into the economic cost. Aiming at the randomness and uncertainty of wind power output, the prediction error of wind power is fuzzily 
processed, and the electric power balance and spinning reserve fuzzy opportunity conditions are established, which are converted into the explicit equivalent. The improved MOPSO was used to solve the multi-objective scheduling model. The following conclusions can be drawn: (1) The traditional single-objective scheduling model with the lowest economic cost as the objective function ignores the impact on the environment. The multi-objective model proposed in this paper not only guarantees the economy, but also reduces the negative impact on the environment to some extent. (2) Although the addition of green certification increases the economic cost, it promotes the consumption of wind power. In addition, the purchase margin and price of green certificates can be adjusted to control the economic cost of the system and pollutant emissions. (3) The uncertainty of wind power output makes the traditional scheduling experience feasible domain change, and the scheduling idea needs to change from deterministic to uncertain. The combination of units considering uncertainty should meet the confidence level required by the system so as to achieve a decision result which takes into account both the economy and reliability. In this paper, the fuzziness of wind power output is transformed into the fuzziness of prediction error, and the fast solution is realized by transforming fuzzy opportunity constraint into the explicit equivalent. (4) The improved MOPSO improves the solving speed and precision, which is suitable for the scheduling model in this paper.

Author Contributions: X.W. and J.T. conceived the theory and built the model; R.W., S.C., J.W., J.X. and Y.C. performed the experiments and analyzed the data; X.W. and J.T. wrote the paper.

Acknowledgments: This research is funded by National Natural Science Foundation of China under grant number 51777027.

Conflicts of Interest: The authors declare no conflict of interest.

\section{References}

1. Ziane, I.; Benhamida, F.; Graa, A.; Salhi, Y. Wind power impact in the environmental/economic dispatch. In Proceedings of the International Conference on Electrical Engineering, Boumerdes, Algeria, 13-15 December 2016; pp. 1-4.

2. Jin, J.; Zhou, D.; Zhou, P.; Miao, Z. Environmental/economic power dispatch with wind power. Renew. Energy 2014, 71, 234-242. [CrossRef]

3. Lund, H.; Münster, E. Modelling of energy systems with a high percentage of CHP and wind power. Renew. Energy 2014, 28, 2179-2193. [CrossRef]

4. Vögelin, P.; Koch, B.; Georges, G.; Boulouchos, K. Heuristic approach for the economic optimisation of combined heat and power (CHP) plants: Operating strategy, heat storage and power. Energy 2017, 121, 66-77. [CrossRef]

5. Sala, J.M. Thermal energy storage (TES) systems for cogeneration and trigeneration systems. In Advances in Thermal Energy Storage Systems; Euskal Herriko Unibertsitatea: Basque, Spain, 2015; pp. 493-509.

6. Botterud, A.; Zhou, Z.; Wang, J.; Sumaili, J.; Keko, H.; Mendes, J.; Bessa, R.J.; Miranda, V. Demand Dispatch and Probabilistic Wind Power Forecasting in Unit Commitment and Economic Dispatch: A Case Study of Illinois. IEEE Trans. Sustain. Energy 2013, 4, 250-261. [CrossRef]

7. Aghaei, J.; Niknam, T.; Azizipanah-Abarghooee, R.; Arroyo, J.M. Scenario-based dynamic economic emission dispatch considering load and;wind power uncertainties. Int. J. Electr. Power Energy Syst. 2013, 47, 351-367. [CrossRef]

8. Yang, S.; Tong, X.; Zhang, H. Study on power dynamic transfer characteristics of wind power generation system. In Proceedings of the Power Electronics and Application Conference and Exposition, Shanghai, China, 5-8 November 2015; pp. 157-161.

9. Lorca, A.; Sun, X.A. Adaptive Robust Optimization with Dynamic Uncertainty Sets for Multi-Period Economic Dispatch Under Significant Wind. IEEE Trans. Power Syst. 2015, 30, 1702-1713. [CrossRef]

10. Gu, B.C.; Chen, Z.M.; Jiv, T.Y.; Zhang, L.L.; Wu, Q.H.; Li, M.S.; Huang, J.H. Quasi-Monte Carlo simulation based economic dispatch with wind power integrated. In Proceedings of the Innovative Smart Grid Technologies-Asia, Melbourne, Australia, 28 November-1 December 2016; pp. 264-269. 
11. Hua, X.; Yuxi, C.; Jian, W.; Agelidis, V. Design of energy dispatch strategy of active distribution network using chance-constrained programming. In Proceedings of the Power and Energy Engineering Conference, Brisbane, Australia, 15-18 November 2016; pp. 1-5.

12. Shahirinia, A.H.; Soofi, E.S.; Yu, D.C. Probability distributions of outputs of stochastic economic dispatch. Int. J. Electr. Power Energy Syst. 2016, 81, 308-316. [CrossRef]

13. Xiong, H.; Xiang, T.; Chen, H.; Lin, F.; Su, J. Research of Fuzzy Chance Constrained Unit Commitment Containing Large-scale Intermittent Power. Proc. CSEE 2013, 33, 36-44.

14. Mueller, S.; Tuth, R.; Fischer, D.; Wille-Haussmann, B.; Wittwer, C. Balancing Fluctuating Renewable Energy Generation Using Cogeneration and Heat Pump Systems. Energy Technol. 2014, 2, 83-89. [CrossRef]

15. Lu, Z.; Yang, Y.; Geng, L.; Pan, L. Low-carbon Economic Dispatch of the Integrated Electrical and Heating Systems Based on Benders Decomposition. Proc. CSEE 2018, 38, 1922-1934.

16. Zhang, L.P.; Chen, L.; Wang, X.; Huang, P.; Ding, M.S.; Li, J. Study on Thermal Storage Device Model and Control Strategy for Cogeneration and Wind Power Heating System. Appl. Mech. Mater. 2015, 740, 460-465. [CrossRef]

17. Wang, Z.; Yang, L.; Li, J.; Ma, T.; Gao, K.; Yang, J. Energy Optimization for Combined System of Wind-electric Energy Storage-regenerative Electric Boiler Considering Wind Consumption. Proc. CSEE 2017, 37, 137-143.

18. Nguyen, T.T.; Vo, D.N.; Dinh, B.H. Cuckoo search algorithm for combined heat and power economic dispatch. Int. J. Electr. Power Energy Syst. 2016, 81, 204-214. [CrossRef]

19. Chanda, C.K.; Maity, D.; Banerjee, S. Economic dispatch solution for cogeneration unit assisted by biogeography based optimization algorithm in competitive environment. In Proceedings of the Australasian Universities Power Engineering Conference (AUPEC), Melbourne, Australia, 19-22 November 2018; pp. 1-5.

20. Jin, X.L.; Li, H.F.; Jin, T.; Xu, X.D.; Wang, M.S.; Meng, J. Economical and Coordinated Dispatch of CHP Based Microgrid with Renewable Energy Resources. Adv. Mater. Res. 2014, 960, 1022-1028. [CrossRef]

21. Ma, L.; Liu, N.; Zhang, J.; Tushar, W.; Yuen, C. Energy Management for Joint Operation of CHP and PV Prosumers Inside a Grid-Connected Microgrid: A Game Theoretic Approach. IEEE Trans. Ind. Inform. 2016, 12, 1930-1942. [CrossRef]

22. Liu, Z.; Chen, Y.; Zhuo, R.; Jia, H. Energy storage capacity optimization for autonomy microgrid considering CHP and EV scheduling. Appl. Energy 2017, 210, 113-125. [CrossRef]

23. Duan, P.; Zhu, J.; Liu, M. Optimal Dispatch of Virtual Power Plant Based on Bi-Level Fuzzy Chance Constrained Programming. Trans. China Electrotech. Soc. 2016, 31, 58-67.

24. Zhang, X.; Liang, J.; Zhang, X.; Zhang, F.; Zhang, L.; Xu, B. Combined Model for Ultra Short-term Wind Power Prediction Based on Sample Entropy and Extreme Learning Machine. Proc. CSEE 2013, 33, $33-40$.

25. Xu, Y.; Hu, Q.; Li, F. Probabilistic Model of Payment Cost Minimization Considering Wind Power and Its Uncertainty. IEEE Trans. Sustain. Energy 2013, 4, 716-724. [CrossRef]

26. Ai, X.; Liu, X. Dynamic Economic Dispatch for Wind Farms Integrated Power System Based on Credibility Theory. Proc. CSEE 2011, 31, 12-18.

(C) 2018 by the authors. Licensee MDPI, Basel, Switzerland. This article is an open access article distributed under the terms and conditions of the Creative Commons Attribution (CC BY) license (http://creativecommons.org/licenses/by/4.0/). 